\title{
Predictors of pregnancy after HIV-positive diagnosis among women in western Jamaica
}

This article was published in the following Dove Press journal:

International Journal of Women's Health

\section{Lea Jean Claye' \\ Swati Sakhuja' \\ Ashley Nutt ${ }^{1}$ \\ Maung Aung ${ }^{2}$ \\ Pauline E Jolly'}

'Department of Epidemiology, University of Alabama at Birmingham, Birmingham, AL, USA; ${ }^{2}$ Epidemiology and Research Unit, Western Regional Health Authority, Ministry of Health, Montego Bay, Jamaica
Correspondence: Pauline E Jolly Department of Epidemiology, School of Public Health, Ryals Building - room 217, University of Alabama at Birmingham, 1665 University Boulevard, Birmingham, AL 35294-0022, USA

Tel +I 205934 I823

Email jollyp@uab.edu
Background: Antiretroviral therapy has minimized mother-to-child transmission of HIV and given hope to HIV-positive women considering pregnancy. In Jamaica, 36\% of HIV-positive pregnant women enrolled in a pediatric/perinatal HIV/AIDS program had repeat pregnancies. Objective: To describe the epidemiology and identify factors associated with pregnancy after HIV diagnosis among HIV-positive women in Western Jamaica.

Methods: A cross-sectional study was designed among HIV-positive women 18-54 years old who either had or did not have at least one pregnancy after HIV-positive diagnosis. A questionnaire was used to collect information on sociodemographic factors and health-seeking, reproductive, and sexual risk behaviors.

Results: A total of 219 HIV-positive women participated in this study. Length of time since HIV diagnosis, CD4 count, and birth-control methods used were significant predictors of pregnancy after HIV diagnosis. Women diagnosed with HIV $<5$ years previously had lower odds for pregnancy after HIV diagnosis (adjusted OR 0.12, 95\% CI 0.02-0.84) compared to those who had been diagnosed $\geq 8$ years previously. Women with CD4 count $<350$ were over six times as likely to have a pregnancy after HIV diagnosis (adjusted OR 6.94, 95\% CI 1.18-40.66). The odds for pregnancy after HIV diagnosis for a woman decreased by $93 \%$ if her children shared the same father (adjusted OR 0.07, 95\% CI 0.006-0.77).

Conclusion: This study identified significant predictors of pregnancy after HIV diagnosis that indicate that integrative family-planning interventions with supportive reproductive counseling are likely to help HIV-positive women obtain early appropriate care and plan the pregnancies they desire.

Keywords: pregnancy, HIV infection, desire for children, HIV disclosure

\section{Introduction}

In $2016,17.8$ million women aged $\geq 15$ years worldwide were estimated to be living with HIV; this constitutes $51 \%$ of all adults living with HIV. ${ }^{1,2}$ The Caribbean remains second to sub-Saharan Africa in global HIV prevalence. ${ }^{3}$ In 2016, 30,000 people were estimated to be living with HIV in Jamaica, of which 11,000 were women aged $\geq 15$ years. $^{4}$ Although the cumulative AIDS case rate in Jamaica is lower for females than for males (504.9 per 100,000 vs 689.3 per 100,000), over time females are accounting for an increased proportion of AIDS cases reported annually. ${ }^{5} \mathrm{HIV}$ prevalence among women of reproductive age (15-49 years) in Jamaica is $1.3 \%{ }^{4}$ Young women aged 15-24 years and adolescent females aged 10-19 years are also contracting HIV at a higher rate than other groups. Four times as many young women in these age groups have been reported with AIDS than young men. ${ }^{6}$ The four parishes in western Jamaica (Westmoreland, Hanover, St. James, and Trelawny) have 
significant tourist-based economies and are among those with the highest cumulative number of HIV cases. ${ }^{7}$

In 2014,8 out of every 1,000 pregnant women $(0.8 \%)$ in Jamaica were infected with HIV, and ten pediatric AIDS cases (children aged 0-9 years) were reported, compared to 21 pediatric AIDS cases in $2011 .^{7}$ Approximately $48 \%$ of HIV-infected women aged $\geq 15$ years and $>95 \%$ of HIVinfected children aged 0-14 years are currently receiving antiretroviral therapy (ART). However, $>95 \%$ of pregnant women receive ART for prevention of mother-to-child transmission (MTCT) of HIV. ${ }^{4}$ MTCT rates in Jamaica dropped from $25 \%-30 \%$ in 2002 to about $1 \%$ in $2015 .{ }^{8}$ Therefore, ART has minimized MTCT of HIV and given HIV-positive women who consider pregnancy hope for their future. In a study on the relationship of pregnancy and HIV progression, it was shown that repeat pregnancies did not have a significant effect on the course of HIV disease. ${ }^{9}$ In Jamaica, 36\% of HIV-positive pregnant women who lived in the urban areas of Kingston and Spanish Town and enrolled in the Kingston Pediatric and Perinatal HIV/AIDS Program had repeat pregnancies. ${ }^{10}$ General knowledge of HIV does not affect unprotected sexual behavior among the women. A focus-group study conducted among some of the HIV-positive women with repeat pregnancies showed that multiple factors affected their decision to continue having children. ${ }^{11}$ These included stability with the male partner, financial support with pregnancy, and the fear of disclosure of HIV-positive status due to dread of "emotional harm and rejection". Therefore, women were unwilling to modify their sexual behavior or use contraceptives. Furthermore, they regarded having children as important in "affirming their well-being and in defining their womanhood". ${ }^{11}$

The Jamaican fertility rate in 2013 was 2.26 children per woman. ${ }^{12}$ The 1993 Jamaican Contraceptive Prevalence Survey reported that $93.5 \%$ of 2,864 women preferred spacing children an average of 2-4 years. ${ }^{13}$ Furthermore, having children in a marriage or committed relationship may give HIV-positive women a sense of normality. ${ }^{14}$ As HIV infection is treated more effectively and HIV-infected women are living longer, healthier lives, it is important to investigate the epidemiology of pregnancy among these women and their attitudes, desires, and decisions regarding childbearing. This will provide health officials with a better understanding of the attitudes of these women regarding the impact of HIV on childbearing and the factors associated with their reproductive decision-making.

In western Jamaica, there were approximately $150 \mathrm{HIV}$ positive women attending antenatal care clinics in 2012 who became pregnant after they knew of their HIV-positive status. This study was conducted among these women and other HIV-positive women attending HIV clinics who had not become pregnant since their HIV diagnosis to describe the epidemiology of, and identify factors associated with, pregnancy after HIV diagnosis.

\section{Methods}

\section{Study design and participant recruitment}

This was designed as a cross-sectional study among HIVpositive women attending clinics at the following hospitals and health centers in the four parishes of western Jamaica: the Noel Holmes Hospital and Lucea Health Center in Hanover, the Falmouth Health Center in Trelawny, the Cornwall Regional Hospital and Type V Health Center in St James, and the Savanna La Mar Health Center in Westmoreland. HIVpositive women in the four parishes were identified from the Prevention of Mother to Child Transmission (PMTCT) register kept at the Cornwall Regional Hospital (the headquarters for the region) and a list was generated. Further, all HIV-positive women in the western region are followed by social workers in addition to their clinicians. There was at least one social worker at each clinic site who helped the study staff identify women who qualified for this study. The list of names generated from the PMTCT register was reviewed by social workers and adherence counselors in each parish to determine if the women were alive, still living in the region, or lost to follow-up care. The social workers and adherence counselors told the women available about the study at their clinic visits and asked if they would be willing to participate. Women who indicated willingness to participate were introduced to the research staff by the social workers and adherence counselors and arrangements were made to meet them at the clinics/ hospitals. HIV-positive women not listed in the PMTCT register were told about the study by the social workers and adherence counselors when they visited the clinics or hospitals for routine care. Those who expressed willingness to participate in the study were then introduced to the research staff.

A consent form was provided to all potential study participants to read, and they were encouraged to ask questions. After all questions were answered to the satisfaction of the women, they were then asked to sign the form. The consent form was read to women who were unable to read, and they were asked to mark an X signifying their consent to participate. The protocol was reviewed and approved by the Institutional Review Board of the University of Alabama at Birmingham, USA and the Western Regional Health Authority, Ministry of Health, Montego Bay, Jamaica, prior to its implementation. Women who were 18-54 years of age, lived in the parishes from January-December 2011, and 
were HIV-positive were eligible to participate in this study. Women were excluded from the study if they were not in the eligible age group, did not live in the region, declined to participate, or were unable or unwilling to visit the clinic during the study period.

Each woman was asked "How many pregnancies have you had since you were diagnosed with HIV?" Based on their responses and confirmation through the PMTCT register, social workers, or adherence counselors, the women were divided into two groups: one group who had at least one pregnancy since HIV-positive diagnosis and the other group who had no pregnancy since HIV-positive diagnosis.

\section{Data collection}

A structured interviewer-administered questionnaire was used to collect sociodemographic information (eg, age, sex, marital status, income, education, and occupation), information on health-seeking behavior (frequency of use of health-care facilities), and obstetric and sexual risk behavior (eg, condom use, number of sexual partners, number of previous pregnancies) from the women. Each interview lasted approximately 30 minutes. Figure 1 shows that 271 women were eligible to participate in the study. A total of 219 agreed (89 who had a pregnancy since HIV diagnosis and 130 who did not), consented, and were enrolled in the study.

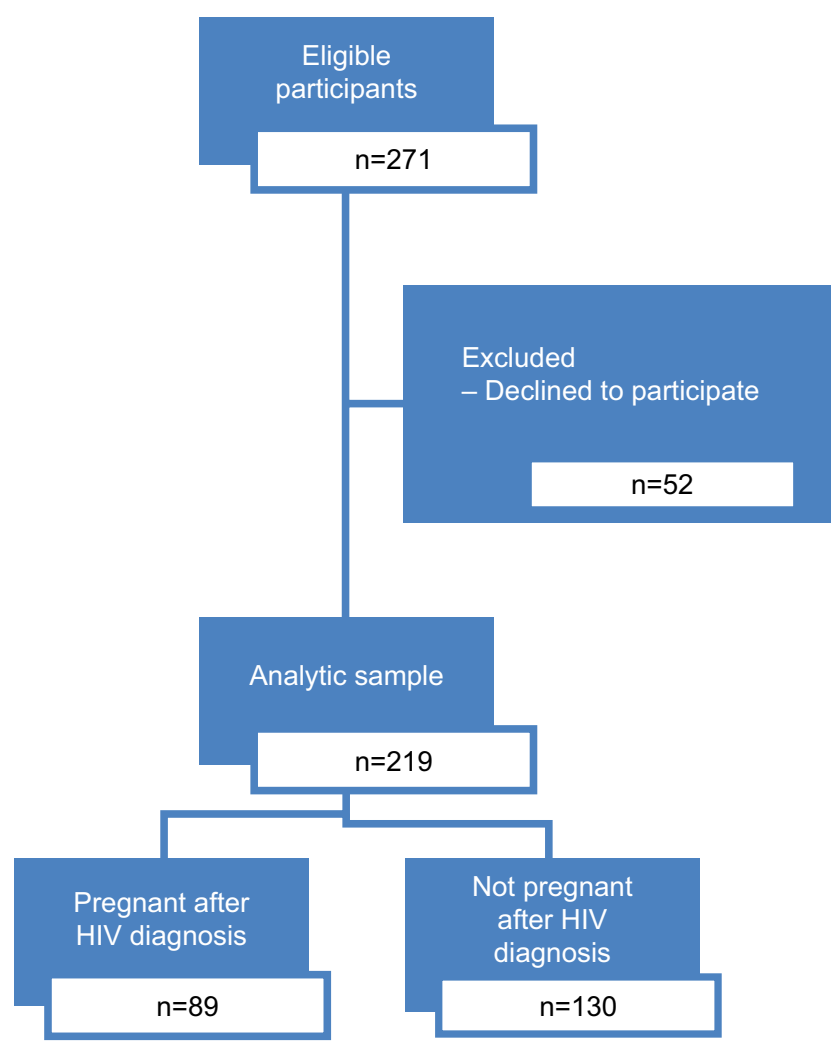

Figure I Inclusion/Exclusion cascade for the analytic sample.

\section{Data analysis}

Descriptive statistics were assessed for all variables and used to summarize the sociodemographic characteristics of the study population. The $\chi^{2}$-test was used to determine the association between pregnancy after HIV-positive diagnosis and predictor variables. Fisher's exact test was used to obtain $P$-values for selected variables that had expected cell counts $<5$. Additionally, multivariable logistic regression was used to determine adjusted associations between pregnancy after HIV diagnosis and sociodemographic and reproductive variables. The initial model included adjustment for age, employment status, length of time since HIV-positive diagnosis, CD4 count, number of sexual partners since HIV-positive diagnosis, children sharing the same father, and facing rejection. Rejection was defined as nonacceptance by others because of HIV infection. It could have been snubbing, ignoring, being given the "cold shoulder", slighting, or shaming of the HIV-positive person. Specific types of rejection mentioned by the participants were rejection by family and community members, discrimination or mistreatment by doctors and nurses, and rejection by other women due to HIV-positive status. The women also feared that they would face rejection from their partners if they discovered their HIVpositive status due to stigma concerning the disease. The final model was further adjusted for use of contraceptive methods for birth control. For all statistical tests, a two-sided $P$-value of $<0.05$ was considered significant, and all analyses were conducted using SAS 9.4 (SAS Institute, Cary, NC, USA).

\section{Results Sociodemographic characteristics of participants by pregnancy after HIV diagnosis}

Table 1 shows the sociodemographic characteristics of the 219 women who were included in the analysis. A significantly higher proportion of women who had a pregnancy after HIV-positive diagnosis when compared to women who did not were $25-34$ years old $(50.6 \%$ vs $38.5 \%, P=0.001)$ and unemployed $(56.2 \%$ vs $50.0 \%, P=0.031)$. Most women reported being single (60.7\%), having had secondary school education (65.7\%), and without income (52.1\%). A significantly lower proportion of women who had a pregnancy after HIV diagnosis had been diagnosed with HIV $<5$ years previously at the time of being interviewed ( $30.2 \%$ vs $52.3 \%, P=0.005$ ). A higher proportion of women who had a pregnancy after HIV-positive diagnosis (32.3\%) had a CD4 count $<350$ when compared with those who did not get pregnant (18.0\%); however, this difference was not statistically significant. 
Table I Sociodemographic characteristics of study participants by pregnancy after HIV diagnosis

\begin{tabular}{|c|c|c|c|c|c|c|c|}
\hline & \multicolumn{7}{|c|}{ Pregnant after HIV-positive diagnosis } \\
\hline & Yes, $n=89$ & $\%$ & No, $n=130$ & $\%$ & Total, $\mathrm{n}=219$ & $\%$ & $P$-value ${ }^{a}$ \\
\hline Age (years) & & & & & & & $0.001 *$ \\
\hline $18-24$ & 20 & 22.5 & 16 & 12.3 & 36 & 16.4 & \\
\hline $25-34$ & 45 & 50.6 & 50 & 38.5 & 95 & 43.4 & \\
\hline $35-44$ & 22 & 24.7 & 42 & 32.3 & 64 & 29.2 & \\
\hline $45-54$ & 2 & 2.2 & 22 & 16.9 & 24 & 11.0 & \\
\hline Parish & & & & & & & 0.714 \\
\hline Hanover & 10 & 11.6 & 17 & 13.2 & 27 & 12.6 & \\
\hline St James & 56 & 65.1 & 85 & 65.9 & $14 \mid$ & 65.2 & \\
\hline Trelawny & 8 & 9.3 & 15 & 11.6 & 23 & 10.7 & \\
\hline Westmoreland & 12 & 13.9 & 12 & 9.3 & 24 & 11.2 & \\
\hline Marital status & & & & & & & 0.606 \\
\hline Married & 10 & 11.2 & 18 & 13.8 & 28 & 12.7 & \\
\hline Single & 53 & 58.4 & 81 & 62.3 & 133 & 60.7 & \\
\hline Common law & 13 & 14.6 & 18 & 13.8 & 31 & 14.2 & \\
\hline Other & 14 & 15.7 & 13 & 10 & 27 & 12.3 & \\
\hline Education level & & & & & & & 0.393 \\
\hline Primary & 14 & 16.1 & 28 & 22.2 & 42 & 19.7 & \\
\hline Secondary & 61 & 70.1 & 79 & 62.7 & 140 & 65.7 & \\
\hline Tertiary & 9 & 10.3 & 10 & 7.9 & 19 & 8.9 & \\
\hline College & 3 & 3.5 & 9 & 7.1 & 12 & 5.6 & \\
\hline Employment status & & & & & & & $0.031 *$ \\
\hline Unemployed & 50 & 56.2 & 65 & 50.0 & 115 & 52.5 & \\
\hline Employed & 29 & 32.6 & 32 & 24.6 & 61 & 27.9 & \\
\hline Self-employed & 10 & 11.2 & 33 & 25.4 & 43 & 19.6 & \\
\hline Weekly income (J\$) & & & & & & & 0.314 \\
\hline 0 & 51 & 57.3 & 63 & 48.5 & 114 & 52.1 & \\
\hline $1-3,999$ & 11 & 12.4 & 18 & 13.9 & 29 & 13.2 & \\
\hline $4,000-5,999$ & 12 & 13.5 & 14 & 10.8 & 26 & 18.9 & \\
\hline$\geq 6,000$ & 15 & 16.9 & 35 & 26.9 & 50 & 22.8 & \\
\hline Period since HIV diagnosis (years) & & & & & & & $0.005^{*}$ \\
\hline$<5$ & 26 & 30.2 & 67 & 52.3 & 93 & 43.5 & \\
\hline $5-<8$ & 34 & 39.5 & 37 & 28.9 & 71 & 33.2 & \\
\hline$\geq 8$ & 26 & 30.2 & 24 & 18.8 & 50 & 23.4 & \\
\hline CD4 (cells $/ \mathrm{mm}^{3}$ blood) & & & & & & & 0.180 \\
\hline$<350$ & 10 & 32.3 & 9 & 18.0 & 19 & 23.5 & \\
\hline$\geq 350$ & 21 & 67.7 & 41 & 82.0 & 62 & 76.5 & \\
\hline
\end{tabular}

Notes: aEstimated using $\chi^{2}$-test for association between pregnancy after HIV and predictor variables and Fisher's exact test for selected variables that had expected count $<5$. Fisher's exact test was used to obtain $P$-values for selected variables that had expected cell counts $<5$. Numbers may not add up to total, due to missing responses. $* P<0.05$.

\section{Birth-control methods by pregnancy status after HIV diagnosis}

Overall, use of hormonal birth-control methods among the women was low (26.0\%). Among women who had a pregnancy after HIV compared to those who did not, use of hormonal methods (primarily birth control pills) was high (36.0\% vs $19.2 \%, P=0.006$; Table 2 ) and use of contraceptive sponges was low $(9.0 \%$ vs $23.9 \%, P=0.005)$. Barrier methods (primarily male condoms) were the most reported form of contraception (63.5\%) used by these women. Additionally, a higher proportion of women who had a pregnancy after HIV-positive diagnosis compared to those who did not reported that they make the decision to use birth control themselves (62.9\% vs $42.5 \%, P=0.016)$ and used birth control measures every time they were sexually active ( $71.9 \%$ vs $53.9 \%, P=0.002)$.

\section{Obstetric and reproductive history by pregnancy status after HIV diagnosis}

Overall, $46.1 \%$ of the women reported being diagnosed with HIV during a pregnancy (Table 3 ). Over $75 \%$ of the women who had a pregnancy after HIV-positive diagnosis said they did not plan for it, and over two-thirds of those resulted from unprotected sex (67.2\%). A significantly higher proportion of women who had a pregnancy after HIV-positive diagnosis compared to those who did not reported having more than one sexual partner ( $35.2 \%$ vs $20.9 \%, P=0.001)$, and a higher proportion reported that their children did not share the same 
Table 2 Use of birth control methods by pregnancy status after HIV diagnosis

\begin{tabular}{|c|c|c|c|c|c|c|c|}
\hline & \multicolumn{7}{|c|}{ Pregnant after HIV-positive diagnosis } \\
\hline & Yes, $\mathbf{n}=\mathbf{8 9}$ & $\%$ & No, $n=130$ & $\%$ & Total, $\mathrm{n}=219$ & $\%$ & $P$-value \\
\hline \multicolumn{8}{|l|}{ Type of birth control used } \\
\hline \multicolumn{7}{|l|}{ Any hormonal method ${ }^{b}$} & $0.006 *$ \\
\hline Yes & 32 & 36.0 & 25 & 19.2 & 57 & 26.0 & \\
\hline No & 57 & 64.0 & 105 & 80.8 & 162 & 74.0 & \\
\hline \multicolumn{7}{|l|}{ Any barrier method ${ }^{c}$} & 0.884 \\
\hline Yes & 57 & 64.0 & 82 & 63.1 & 139 & 63.5 & \\
\hline No & 32 & 36.0 & 48 & 36.9 & 80 & 36.5 & \\
\hline \multicolumn{7}{|l|}{ Contraceptive sponge } & $0.005^{*}$ \\
\hline Yes & 8 & 9.0 & 31 & 23.9 & 39 & 17.8 & \\
\hline No & 81 & 91.0 & 99 & 76.1 & 180 & 82.2 & \\
\hline \multicolumn{7}{|l|}{ Frequency of birth control use } & $0.002^{*}$ \\
\hline Do not use at all & 4 & 4.5 & 8 & 6.2 & 12 & 5.5 & \\
\hline Every time & 64 & 71.9 & 70 & 53.9 & 134 & 61.2 & \\
\hline Most/some of the time & 14 & 15.7 & 15 & 11.5 & 29 & 13.2 & \\
\hline Other & 7 & 7.9 & 37 & 28.5 & 44 & 20.1 & \\
\hline \multicolumn{7}{|c|}{ Problems with regular birth control use } & 0.626 \\
\hline None & 56 & 62.9 & 81 & 62.3 & 137 & 62.6 & \\
\hline Side effects & 15 & 16.9 & 24 & 18.5 & 39 & 17.8 & \\
\hline Inconvenience & 5 & 5.6 & 3 & 2.3 & 8 & 3.7 & \\
\hline Doesn't like taking the pill & 13 & 14.6 & 22 & 16.9 & 35 & 16.0 & \\
\hline \multicolumn{7}{|l|}{ Who decides on birth control } & $0.016 *$ \\
\hline Myself & 56 & 62.9 & 54 & 42.5 & 110 & 50.9 & \\
\hline My partner & 1 & 1.1 & 4 & 3.2 & 5 & 2.3 & \\
\hline Both of us & 28 & 31.5 & 54 & 42.5 & 82 & 38.0 & \\
\hline Other/not answered & 4 & 4.5 & 15 & 11.8 & 19 & 8.8 & \\
\hline
\end{tabular}

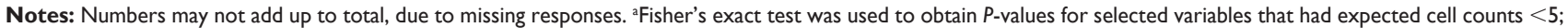
estimated using $\chi^{2}$-test for association between repeat pregnancy and predictor variables. 'Includes birth control pills, birth control patch, and hormonal injections. Includes intrauterine device, male condom, female condom, and cervical cap. $* P<0.05$.

father (91.0\% vs $78.1 \%, P=0.012)$. A significantly higher proportion of women who had a pregnancy after HIV-positive diagnosis had more than one child ( $79.8 \%$ vs $60 \%, P=0.005)$. Only $5.9 \%$ of the women reported breastfeeding their babies after they had been diagnosed with HIV, but significantly more women who had a pregnancy after HIV diagnosis reported breastfeeding while HIV-positive ( $10.1 \%$ vs $3.0 \%, P=0.031$ ).

\section{HIV disclosure and support by pregnancy status after HIV diagnosis}

Less than half of the women (in both groups) had disclosed their HIV-positive status to their spouse or partner (41\%), family, and/or friends ( $42.5 \%$; Table 4). A higher proportion of women who had a pregnancy ( $28.6 \%$ vs $10.8 \%)$ reported facing rejection by a family member, friend, or colleague $(P=0.02)$ and were more likely to agree with the statement "Women are happy that they are HIV-positive, yet can still have children" (69.7\% vs 56.1\%) when compared to those who did not have a pregnancy. Women who had a pregnancy after HIV-positive diagnosis compared to those who did not were less likely to agree that being HIV-positive added a burden to their family ( $44.9 \%$ vs $64.6 \%$ ). Additionally, women who had a pregnancy after HIV-positive diagnosis compared to those who did not were significantly less likely to fill their prescriptions on time ( $66.7 \%$ vs $79.3 \%, P=0.045)$ or to report that they took ART for their own care (14.6\% vs $59.4 \%$, $P<0.001)$. Reasons given for not filling prescriptions on time included fear of disclosure, lack of time, and lack of money.

\section{Multivariable logistic regression of predictors for pregnancy after HIV diagnosis}

Both multivariable logistic regression models identified length of time diagnosed with HIV, CD4 cell count, and children sharing the same father as independent predictors of pregnancy after HIV-positive diagnosis among the 
Table 3 Obstetric and reproductive history by pregnancy status after HIV diagnosis

\begin{tabular}{|c|c|c|c|c|c|c|c|}
\hline & \multicolumn{7}{|c|}{ Pregnant after HIV-positive diagnosis } \\
\hline & Yes, $n=89$ & $\%$ & No, $n=130$ & $\%$ & Total, $\mathrm{n}=\mathbf{2 1} 19$ & $\%$ & $P$-value ${ }^{a}$ \\
\hline Participant diagnosed during pregnancy & & & & & & & 0.055 \\
\hline Yes & 48 & 53.9 & 53 & 40.8 & 101 & 46.1 & \\
\hline No & 41 & 46.1 & 77 & 59.2 & 118 & 53.9 & \\
\hline Planned pregnancies after HIV diagnosis & & & & & & & $<0.00 I^{*}$ \\
\hline None & 67 & 76.1 & 130 & 100.0 & 197 & 90.4 & \\
\hline More than one & 21 & 23.9 & 0 & - & 21 & 9.6 & \\
\hline Did unprotected sex result in any of those unplanned pregnancies? & & & & & & & - \\
\hline Yes & 45 & 67.2 & - & - & 45 & 67.2 & \\
\hline No & 22 & 32.8 & - & - & 22 & 32.8 & \\
\hline Number of children you desired? & & & & & & & 0.349 \\
\hline None & 10 & 11.7 & 14 & 11.0 & 24 & 11.3 & \\
\hline One & 6 & 7.1 & 17 & 13.4 & 188 & 10.6 & \\
\hline More than one & 69 & 81.2 & 96 & 75.6 & 165 & 77.8 & \\
\hline Breastfed while HIV-positive & & & & & & & $0.03 I^{*}$ \\
\hline Yes & 9 & 10.1 & 4 & 3.0 & 13 & 5.9 & \\
\hline No & 80 & 89.9 & 126 & 96.9 & 206 & 94.1 & \\
\hline Have you had adverse birth outcomes? & & & & & & & 0.190 \\
\hline Yes & 35 & 39.3 & 40 & 30.8 & 75 & 34.3 & \\
\hline No & 54 & 60.7 & 90 & 69.2 & 144 & 65.8 & \\
\hline How many children do you currently have? & & & & & & & $0.005^{*}$ \\
\hline None & 4 & 4.5 & 19 & 14.6 & 23 & 10.5 & \\
\hline One & 14 & 15.7 & 33 & 25.4 & 47 & 21.5 & \\
\hline More than one & 71 & 79.8 & 78 & 60.0 & 149 & 68.0 & \\
\hline Number of HIV-positive children & & & & & & & 0.196 \\
\hline None & 95 & 92.2 & 77 & 86.5 & 172 & 89.6 & \\
\hline One or more & 8 & 7.8 & 12 & 13.5 & 12 & 10.4 & \\
\hline Do your children share a father? & & & & & & & $0.012 *$ \\
\hline Yes & 8 & 9.0 & 28 & 21.9 & 36 & 16.6 & \\
\hline No & 81 & 91.0 & 100 & 78.1 & 181 & 83.4 & \\
\hline Number of sexual partners after HIV diagnosis & & & & & & & $0.00 I^{*}$ \\
\hline None & 2 & 2.3 & 21 & 16.3 & 23 & 10.6 & \\
\hline One & 55 & 62.5 & 81 & 62.8 & 136 & 62.7 & \\
\hline More than one & 31 & 35.2 & 27 & 20.9 & 58 & 26.7 & \\
\hline
\end{tabular}

Notes: Numbers may not add up to total, due to missing responses. ${ }^{a}$ Estimated using $\chi^{2}$-test for association between repeat pregnancy and predictor variables; Fisher's exact

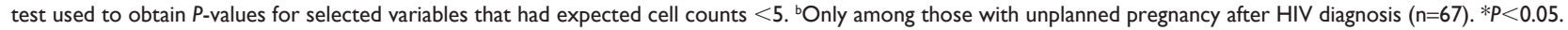

women (Table 5). The odds of pregnancy after HIV-positive diagnosis decreased $85 \%-88 \%$ among women diagnosed with HIV < 5 years (model 1, OR 0.15, 95\% CI 0.02-0.95; model 2, OR 0.12, 95\% CI 0.02-0.84) and 93\%-94\% among women whose children shared the same father (model 1, OR 0.06, 95\% CI 0.006-0.56; model 2, OR 0.07, 95\% CI 0.006-0.77). However, women with a lower CD4 count $(<350)$ were over 6.6 times more likely to have had a pregnancy after HIV-positive diagnosis (adjusted OR 6.61, 95\% CI 1.19-36.71; adjusted OR 6.94, 95\% CI 1.18-40.66) compared to women with a higher CD4 count.

\section{Discussion}

In this study, length of time since HIV diagnosis, CD4 count of $<350$, and children not sharing the same father were found to be significant predictors of pregnancy after
HIV diagnosis. In our bivariate analysis, significantly higher proportions of women aged 25-34 years had a pregnancy after HIV-positive diagnosis. It is understandable that most women, whether infected with HIV or not, would have had children by 35 years of age. The World Factbook reports that the mean age at first birth in Jamaica is 21.2 years. ${ }^{15}$ We adjusted for age in our multivariate models. Therefore, age did not impact our significant findings. It should also be pointed out that reporting marital status as single does not mean that these women did not have visiting male sexual partners. In fact, our finding that $60.7 \%$ of women reported single status agrees well with a study conducted by Brody that reported that $35 \%$ of women were living in consensual unions, $15 \%$ were in legal marriages, and 50\% lived alone, but most had male partners who visited them regularly. ${ }^{16}$ Chamie reported that $60 \%$ of births in Jamaica occurred outside marriage. ${ }^{17}$ 
Table 4 HIV disclosure, perceived attitudes toward HIV-positive status, clinic attendance, and reason for taking ART by pregnancy status after HIV diagnosis

\begin{tabular}{|c|c|c|c|c|c|c|c|}
\hline \multirow[t]{2}{*}{ Variable } & \multicolumn{7}{|c|}{ Pregnant after $\mathrm{HIV}^{+}$diagnosis } \\
\hline & Yes, $n=89$ & $\%$ & No, $n=130$ & $\%$ & Total, $\mathrm{n}=219$ & $\%$ & $P$-value ${ }^{a}$ \\
\hline Who is aware of your HIV status? & & & & & & & 0.603 \\
\hline No one & 7 & 8.1 & 15 & 12.0 & 22 & 10.4 & \\
\hline Spouse/partner & 39 & 48.8 & 48 & 38.4 & 87 & 41.0 & \\
\hline Family/friends & 37 & 42.5 & 53 & 42.4 & 90 & 42.5 & \\
\hline Doctor/nurse/other HCW & 4 & 4.6 & 9 & 7.2 & 13 & 6.1 & \\
\hline Have you faced rejection because of your HIV-positive status? & & & & & & & $0.020 *$ \\
\hline No & 43 & 51.2 & 73 & 60.8 & 116 & 56.9 & \\
\hline Family member & 14 & 16.7 & 9 & 7.5 & 23 & 11.3 & \\
\hline Colleague/friend & 10 & 11.9 & 4 & 3.3 & 14 & 6.9 & \\
\hline Doctor/social worker & 8 & 9.5 & 12 & 10.0 & 20 & 9.8 & \\
\hline Others & 9 & 10.7 & 22 & 18.3 & 31 & 15.2 & \\
\hline $\begin{array}{l}\text { Pregnant women who are HIV-positive add burden to } \\
\text { their family }\end{array}$ & & & & & & & $0.014 *$ \\
\hline Agree & 40 & 44.9 & 84 & 64.6 & 124 & 56.6 & \\
\hline Disagree & 38 & 42.7 & 34 & 26.2 & 72 & 32.9 & \\
\hline Do not know & 11 & 12.4 & 12 & 9.2 & 23 & 10.5 & \\
\hline $\begin{array}{l}\text { Women are happy that they are HIV-positive, yet can } \\
\text { still have children }\end{array}$ & & & & & & & 0.110 \\
\hline Agree & 62 & 69.7 & 73 & 56.1 & 135 & 61.6 & \\
\hline Disagree & 22 & 24.7 & 43 & 33.1 & 65 & 29.7 & \\
\hline Do not know & 5 & 5.6 & 14 & 10.8 & 19 & 8.7 & \\
\hline Do you go for clinic appointments? & & & & & & & 0.211 \\
\hline Yes & 71 & 79.8 & 112 & 86.2 & 183 & 83.6 & \\
\hline No & 18 & 20.2 & 18 & 13.8 & 36 & 16.4 & \\
\hline Do you fill your prescription on time? & & & & & & & $0.045^{*}$ \\
\hline Yes & 58 & 66.7 & 88 & 79.3 & 146 & 73.7 & \\
\hline No & 29 & 33.3 & 23 & 20.7 & 52 & 26.3 & \\
\hline Reason for taking ART & & & & & & & $<0.00 I^{*}$ \\
\hline рMTCT & 23 & 25.8 & 18 & 14.1 & $14 \mid$ & 18.9 & \\
\hline Myself & 13 & 14.6 & 76 & 59.4 & 89 & 41.0 & \\
\hline Both & 52 & 58.4 & 22 & 17.2 & 74 & 34.1 & \\
\hline Neither & I & 1.1 & 12 & 9.4 & 13 & 6.0 & \\
\hline
\end{tabular}

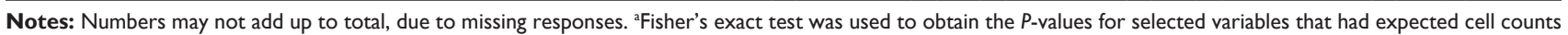
of less than 5; estimated using $\chi^{2}$-test for association between repeat pregnancy and predictor variables. $* P<0.05$.

Abbreviations: ART, antiretroviral therapy; PMTCT, prevention of mother-to-child transmission.

Women who had HIV $<5$ years were less likely to have had a pregnancy after diagnosis than women who had HIV $\geq 8$ years. It may be that women with HIV for longer had more time to deal with their infection, get on ART, and felt more comfortable about getting pregnant again. Longer duration on ART has been found to be associated with desire for children. ${ }^{18}$ HIV-seropositive status may have modified but not remove reproductive desires in the women. Family is highly valued in Jamaican culture, and as HIV-positive women live longer, the likelihood of pregnancy after HIVpositive diagnosis increases. ${ }^{19}$ Also, since reproductive health surveys in Jamaica have revealed that $>40 \%$ of pregnancies are unplanned, it is understandable that the longer the period after HIV-positive diagnosis, the more likely a woman is to get pregnant. ${ }^{20}$ This finding suggests that HIV interventions and strategies should be tailored to support the fertility goals of HIV-positive women. Women with pregnancies after HIV-positive diagnosis also had lower CD4 counts. This may have been due to a longer period of HIV infection and the time that it took for the women to get on ART.

Women who became pregnant after HIV-positive diagnosis were less likely to have children with the father of their other child/children. In a study conducted in Barbados, a majority of women (73.9\%) who had a pregnancy after HIV-positive diagnosis had children by different fathers, and $69.6 \%$ of the women were ambivalent about sharing their HIV-positive status with their partners. ${ }^{21}$ These findings may indicate that women who have pregnancies post-HIV diagnosis are in relationships with men who did not father their previous children, possibly to avoid disclosure. It is possible that the women may have infected or been infected by the father of their previous children and moved on to a new partner who did 
Table 5 Adjusted ORs for factors associated with pregnancy after HIV diagnosis among HIV-positive women in western Jamaica

\begin{tabular}{|c|c|c|}
\hline & Model I & Model 2 \\
\hline & OR $(95 \% \mathrm{Cl})$ & OR $(95 \% \mathrm{CI})$ \\
\hline \multicolumn{3}{|c|}{ Period since HIV diagnosis (years) } \\
\hline$<5$ & $0.15(0.02-0.95)^{*}$ & $0.12(0.02-0.84)^{*}$ \\
\hline $5-<8$ & $0.81(0.13-5.24)$ & $0.54(0.08-3.82)$ \\
\hline$\geq 8$ & Reference & Reference \\
\hline \multicolumn{3}{|c|}{ CD4 (cells $/ \mathrm{mm}^{3}$ blood) } \\
\hline$<350$ & $6.6 I(I .19-36.7 I)^{*}$ & $6.94(1.18-40.66)^{*}$ \\
\hline$\geq 350$ & Reference & Reference \\
\hline \multicolumn{3}{|c|}{ Do your children share the same father? } \\
\hline Yes & $0.06(0.006-0.56)^{*}$ & $0.07(0.006-0.77)^{*}$ \\
\hline No & Reference & Reference \\
\hline \multicolumn{3}{|c|}{ Number of sexual partners after HIV diagnosis } \\
\hline None & Reference & Reference \\
\hline One & $0.38(0.02-6.83)$ & $0.20(0.007-5.7 I)$ \\
\hline More than one & $0.45(0.02-8.69)$ & $0.2 I(0.006-7.07)$ \\
\hline \multicolumn{3}{|c|}{ Have you faced rejection because of your HIV- } \\
\hline \multicolumn{3}{|c|}{ positive status? } \\
\hline Yes & $3.66(0.77-17.45)$ & $4.35(0.8 I-23.44)$ \\
\hline No & Reference & Reference \\
\hline
\end{tabular}

Notes: Model I, adjusted for age and employment status, length of time with HIV, CD4 count, children sharing the same father, number of sexual partners after HIV diagnosis, and having faced rejection because of HIV-positive status; model 2, model I plus adjustment for methods for birth control used. $* P<0.05$.

not know their HIV-positive status. A World Health Organization study reported that $16 \%-86 \%$ of HIV-infected individuals in developing countries did not disclose their HIV-positive status to their sexual partners. ${ }^{22}$ Disclosure is associated with safer sex, increased uptake of preventive services and social and material support, and can reduce the risk of HIV transmission by $17.9 \%-40.6 \%$ relative to nondisclosure. ${ }^{23-25}$ However, disclosure has also resulted in negative outcomes, such as violence, abandonment, and discrimination. ${ }^{26,27}$ It is possible that in this study, the women did not disclose their HIV-positive status to new partners for fear of repercussions, such as termination of relationships and loss of financial support. ${ }^{28}$ Additionally, this finding may explain the result of the women having multiple sexual partners that in turn resulted in HIV transmission. Therefore, sexual and reproductive health services and social support for women who are not in steady relationships but seeking safe contraceptive strategies should be strengthened.

Research in Malawi found that all HIV-positive women involved in a study on fertility wished to have their own child. ${ }^{29}$ Reasons given for this included the desire to please their husbands, fear of losing their husbands if they did not bear children, knowledge that ART would help prevent their children from being HIV-positive, and proving to others that they could bear children. ${ }^{28}$ In the Jamaican context, pregnancy has been noted to change a woman's perception of herself and aid her to develop a sense of pride in her reproductive capacity. ${ }^{16}$ As such, a woman's reproductive role was at times even more meaningful than her role as a mother. Prevailing social and cultural norms dictate that having children is a part of a woman's identity and a symbol of a successful relationship with her partner or husband. Many Jamaicans think that it is not "normal" to be in a marriage or a committed relationship with no children. Therefore, having children in a marriage or committed relationship gives HIV-positive women a sense of normalcy. ${ }^{14}$

\section{Limitations}

This study has certain limitations that should be considered in interpreting the results. The first is that the small sample might have prevented significant findings for variables other than those found significant in the study. The women in the study were recruited from health centers and hospitals, so the findings may not be generalizable to HIV-positive women who do not access these facilities. The data were self-reported and may be subject to social desirability bias. However, the women's reports on pregnancy/no pregnancy post-HIV diagnosis were confirmed through the PMTCT register for the region and from the knowledge of the social workers and adherence counselors. All HIV-positive women who could be located were told of the study; therefore, recruitment bias did not play a role. Regardless of the limitations, this study identified such factors as longer time since HIV-positive diagnosis, $\mathrm{CD} 4$ count $<350$, and children not sharing the same father as significant predictors of pregnancy after HIV-positive diagnosis. Integrative family planning interventions with supportive 
reproductive counseling that addresses these factors are likely to help HIV-positive women access early and appropriate care and plan for the number of children they desire.

\section{Implications for practice and policy}

Family is highly valued in Jamaican culture, and pregnancy helps women develop a sense of pride in their reproductive capacity. Therefore, as HIV-positive women live longer, the likelihood of pregnancy after HIV diagnosis increases. This finding can be used to develop intervention strategies tailored to help HIV-positive women examine their fertility goals, prevent unplanned pregnancies, and plan for the family size they desire. There is need for attention for more comprehensive HIV and contraceptive counseling, as well as social worker visits that ensure women are knowledgeable about their HIV infection and the risks associated with noncompliance with contraceptive use and pregnancy. Reeducation of health-care providers on secure methods of contraception, such as intrauterine devices for women, will allow HIV-positive women to be more decisive in childbearing. Addressing birth outcomes and child welfare seems also to be an important area that needs attention by the health-care system. Many women expressed concern over the welfare of their children. Many had previous poor birth outcomes and were wary of becoming pregnant, due to their HIV-positive status. Social workers and health-care staff should continue sharing precautionary measures that women can take, as well as success stories from women who have taken heed of recommendations and delivered healthy non-HIV-infected babies. Region-wide training of health-care staff promoting HIV sensitivity and confidentiality seems to be needed, since a number of women said that they had been mistreated by health-care staff (doctors and nurses), who in some cases had disclosed participants' HIV-positive status to others.

The study results also indicate that women who become pregnant post-HIV diagnosis are in relationships with men who had not fathered their previous children. Sexual and reproductive health services and social support for HIVpositive women who are not in steady relationships but seeking safe contraceptive strategies should be strengthened. Promotion of support groups may also help in addressing the matters discussed, as well as the problems associated with HIV disclosure, especially to sexual partners. The majority of the women who attended support groups found the experience to be positive, and requested that more informal group discussions take place. Women who did not attend support groups expressed concerns of being in a group with people they did not know and the possibility of group members changing often. Social workers and health staff could work with these women to help them become more comfortable about participating in support groups.

\section{Acknowledgments}

We thank the women who participated in this study, as well as the staff members at the hospitals and clinics that facilitated this study. This research was funded by Minority Health International Research Training (MHIRT) grant T37-MD001448 from the National Institute on Minority Health and Health Disparities, National Institutes of Health, Bethesda, MD, USA, and the Western Regional Health Authority (WRHA), Montego Bay, Ministry of Health, Jamaica.

\section{Disclosure}

The authors report no conflicts of interest in this work.

\section{References}

1. World Health Organization. Global Health Observatory Data: number of women living with HIV. 2016. Available from: http://www.who.int/ gho/hiv/epidemic_status/cases_adults_women_children/en. Accessed March 29, 2017.

2. American Foundation for Aids Research. Statistics: women and HIV/ AIDS. 2017. Available from: http://www.amfar.org/about-hiv-and-aids/ facts-and-stats/statistics--women-and-hiv-aids. Accessed July 6, 2018.

3. Avert. HIV and AIDS in Latin America: the Caribbean regional overview. 2018. Available from: https://www.avert.org/professionals/ hiv-around-world/latin-america/overview. Accessed May 21, 2018.

4. Joint United Nations Programme on HIV/AIDS. Jamaica. 2017. Available from: http://www.unaids.org/en/regionscountries/countries/ jamaica. Accessed May 21, 2018.

5. Jamaica Information Service. Status check: facts and figures on HIV/ AIDS in Jamaica. 2018. Available from: https://jis.gov.jm/features/ hivaids. Accessed May 21, 2018.

6. Jamaica Gleaner. Alarming rate of HIV/AIDS infection among young women. 2018. Available from: http://jamaica-gleaner.com/ gleaner/20120210/lead/lead2.html. Accessed May 21, 2018.

7. Jamaica Ministry of Health. HIV epidemiological profile 2014: facts and figures. 2014. Available from: http://moh.gov.jm/wp-content/ uploads/2015/07/2014-HIV-Epi-Update.pdf. Accessed March 29, 2017.

8. Christie CDC, Palmer PM, Tomlinson J, et al. Achieving elimination of vertical transmission of HIV in Jamaica. Ann Public Health Res. 2017;4(2):1091-1099.

9. Minkoff H, Hershow R, Watts DH, et al. The relationship of pregnancy to human immunodeficiency virus disease progression. Am J Obstet Gynecol. 2003;189(2):552-559.

10. Johnson N, Mullings AA, Harvey KM, et al. HIV seroprevalence, uptake of interventions to reduce mother-to-child transmission and birth outcomes in greater Kingston, Jamaica. West Indian Med J. 2004;53(5):297-302.

11. Rodriquez L, White S, Frankson M, Billings C, Christie C. Factors influencing repeat pregnancies in HIV-positive mothers in Jamaica. Poster presented at: XVII International AIDS Conference; August 3-8 2008, Mexico City.

12. Trading Economics. Jamaica: fertility rate, total (births per woman). 2017. Available from: http://www.tradingeconomics.com/jamaica/fertility-ratetotal-births-per-woman-wb-data.html. Accessed May 15, 2017.

13. McFarlane CP, Friedman JS, Morris L. Knowledge and attitudes towards family, contraception and AIDS: 1993 Jamaica contraceptive prevalence survey. 1994. Available from: http://www.hivgateway.com/entry/57d9 d4d6672f0d112353db6c8584469f. Accessed July 6, 2018. 
14. Cooper D, Harries J, Myer L, Orner P, Bracken H, Zweigenthal V. "Life is still going on": reproductive intentions among HIV-positive women and men in South Africa. Soc Sci Med. 2007;65(2): 274-283.

15. Central Intelligence Agency. Mother's mean age at first birth. Available from: https://www.cia.gov/library/publications/resources/the-worldfactbook/fields/print_2256.html. Accessed May 25, 2018.

16. Brody EB. The meaning of first pregnancy and the first child in Jamaica. In: Carenza L, Zichella L, editors. Emotion and Reproduction: 5th International Congress of Psychosomatic Obstetrics and Gynecology. New York: Academic Press; 1979:473-475.

17. Chamie J. Out-of-wedlock births rise worldwide. 2017. Available from: https://yaleglobal.yale.edu/content/out-wedlock-births-rise-worldwide. Accessed May 25, 2018.

18. Mohammed F, Assefa N. Determinants of desire for children among HIV-positive women in the Afar region, Ethiopia: case control study. PLoS One. 2016;11(3):e0150566.

19. Marriage and Family Encyclopedia. Caribbean families: parent-child relationships. Available from: http://family.jrank.org/pages/207/ Caribbean-Families-Parent-Child-Relationships.html. Accessed May 15, 2017.

20. Jamaica Ministry of Health. Jamaica National Integrated Strategic Plan for Sexual and Reproductive Health and HIV 20142019. 2016. Available from: http://www.moh.gov.jm/wp-content/ uploads/2016/05/Final-National-Integrated-Strategic-Plan-2014-2019with-SRH-Validation.pdf. Accessed May 17, 2018.

21. Kumar A, St. John MA. Knowledge, attitudes, and sexual practice among the HIV infected women with repeated childbirths in Barbados. J HIV/AIDS Prev Educ Adolesc Child. 2002;4(2-3):53-63.
22. World Health Organization. HIV status disclosure to sexual partners: rates, barriers and outcomes for women. 2004. Available from: http://apps. who.int/iris/bitstream/handle/10665/42717/9241590734_summary.pdf; jsessionid=6C7A39EC2DE1A81D102B795C8F16605E ? sequence=2. Accessed May 17, 2018.

23. Duru OK, Collins RL, Ciccarone DH, et al. Correlates of sex without serostatus disclosure among a national probability sample of HIV patients. AIDS Behav. 2006;10(5):495-507.

24. Deribe K, Woldemichael K, Wondafrash M, Haile A, Amberbir A. Disclosure experience and associated factors among HIV positive men and women clinical service users in Southwest Ethiopia. BMC Public Health. 2008;8:81.

25. Pinkerton SD, Galletly CL. Reducing HIV transmission risk by increasing serostatus disclosure: a mathematical modeling analysis. AIDS Behav. 2007;11(5):698-705.

26. Akani CI, Erhabor O, Rate EO. Rate, pattern and barriers of HIV serostatus disclosure in a resource-limited setting in the Niger delta of Nigeria. Trop Doct. 2006;36(2):87-89.

27. Medley A, Garcia-Moreno C, McGill S, Maman S. Rates, barriers and outcomes of HIV serostatus disclosure among women in developing countries: implications for prevention of mother-to-child transmission programmes. Bull World Health Organ. 2004;82(4):299-307.

28. Mphatswe W, Maise H, Sebitloane M. Prevalence of repeat pregnancies and associated factors among teenagers in KwaZulu-Natal, South Africa. Int J Gynaecol Obstet. 2016;133(2):152-155.

29. Biseck T, Kumwenda S, Kalulu K, Chidziwisano K, Kalumbi L. Exploring fertility decisions among pregnant HIV-positive women on antiretroviral therapy at a health centre in Balaka, Malawi: a descriptive qualitative [sic]. Malawi Med J. 2015;27(4):128-134.
International Journal of Women's Health

\section{Publish your work in this journal}

The International Journal of Women's Health is an international, peerreviewed open-access journal publishing original research, reports, editorials, reviews and commentaries on all aspects of women's healthcare including gynecology, obstetrics, and breast cancer. The manuscript management system is completely online and includes

\section{Dovepress}

a very quick and fair peer-review system, which is all easy to use. Visit http://www.dovepress.com/testimonials.php to read real quotes from published authors. 